\title{
https://doi.org/10.24297/ijmit.v15i.8684
}

\section{Investors' Attention and its effect on Saudi Stock Returns}

\author{
Hesah Aljarboa \\ King Saud University \\ Hesah.jarboa@gmail.com
}

\begin{abstract}
The study examines the individual investor's intention effect of attention-grabbing stocks such as stocks in the news, stock experiencing high abnormal trading, and stocks with high returns. Attention driven trading results from an individual investor's ability to process information when being exposed to a large amount of information. The study includes Google's Search Volume Index (SVI) as a proxy for investor attention. Thus, preferences of certain stocks determine decision making after attention has determined the selected stock in which trading is increased.
\end{abstract}

Keywords: Attention, Google Trends, Investors, Search Volume.

\section{Introduction}

Traditional financial theories support the assumption of rationality (Fama, 1965a, 1965b). Investors are portrayed to be attentive to new or emerging information and able to process such information to incorporate such realization in their decision-making process. Classical theories suggest that information is immediately reflected into stock prices. However, existing empirical evidence postulate that investors are limited in terms of the amount of information they can process (Chang, 2008). When being faced with an abundant level of information, investors tend to fail in properly processing such information. In contrast to traditional theories recent research show that irrationality is present in the market and investors do rely on random transactions which are not justifiable by such traditional theories (Chang, 2008).

In modern finance research, scholars have started to consider the aspects of psychology and social science theories to shed more light on the efficiency of financial markets and try to explain different stock market anomalies. The stock markets are viewed as a structure of human exchanges in which psychological biases may affect financial markets (Kahneman \& Tversky, 1979). Hence, differing psychological traits amongst investors reflects upon investor's behavior and trading outcomes.

Several recent studies have suggested that investor differing buying performance could be drawn back to their attention driven behavior. Investor attention is seen to be imbedded in assetprices, where news and information is not solely reflected on prices until individual investors pay attention to it (Barber \& Odean, 2008; Da et al., 2011). Scholars also suggest that individual investors might be limited in their choice of investments based on those that have caught their attention (Odean, 1998).

In recent years, with the presence of the digital age, investor attention has been stimulated more than ever with the emergence of internet-based activities. The accessibility of information is altered, and such new means of information searching has made it more convenient and less costly than that of traditional information collection process. An increase number of searching on the internet for a certain asset of investment has been seen as an indicator for investor attention (Da et al., 2011). Saudi Arabia has witnessed the revelation of the Internet in which citizens rely on the Internet on an accelerating basis and has become essential in the individual's everyday activities 
In this paper, the study investigates investor attention and its effect on stock prices and trading volume. Previous studies on investor attention concentrated on developed markets in which such markets are more efficient than that of the Saudi market. Our results show that Saudi market prices are altered with the release of new information. The paper will first reflect upon a brief literature review of previous studies on investor attention and the infrastructure of the Saudi market. Then, the methodology and data collection is considered. Finally, we discuss of the main findings will be mentioned.

\section{Literature Review}

The Saudi market is considered one of the non-developed markets internationally. To promote economic growth, the government has acknowledged the importance of the financial sector in activating savings and directing resources to economic doings. To this effect, the Saudi government has been sponsoring the expansion of a competent banking system and a well-developed financial market to aid in the economic and fiscal growth of the Saudi economy (Samargandi et al., 2014).

The Saudi stock market has been booming impulsively being backed up by a rising economy, in which initial public offerings and new listings are increasing (Haddad \& Hakim, 2008). Over the past decade and a half, the Saudi market index has witnessed unprecedented rates in growth. It has reached to its highest levels in February 2006 , in which it hit 20,634 points. However, the market has been moving downwards ever since after market regulators have been implemented. The market plunge has been provoked by several factors. The most extreme factors are traced back to the ignorance of investment fundamental and the presence of small and new investors. Such investors naively make their investing decisions as their attention is driven to stocks with news topics being circulated from different means. Hence, Irrational exuberance is a result of these unreasonable trading to such attention-grabbing stocks.

Investor attention is an important indicator of investing behavior of an individual. Scholars, in the psychological arena, have found that the dominant cognitive processing capacity of a single human brain has its limits (Pashler, Johnston, \& Ruthruff, 2001). Hence, the function of the human brain is described by being impotent of multitasking and only being able to concentrate on one task at a given time. The process of processing a vast amount of information at a given time period is hard for the human mind to endure. Therefore, the human being selectively prefers to focuses on information that is offered with some sort of stimuli as opposed to others. The human being is found to selectively attend to certain stimuli or aspect of it, in which a preference to a certain object over the other is reached (Kahneman, 1973). Berlyne (1960) proposed that the power of attention is connected with the level of arousal and provocativeness that is controlled by the stimuli that controls the individual. When attention is sought in an activity that the individual is voluntarily engaged in, the activity at hand attends to the stimuli due to the reason that such activities are relevant to the task at hand (Pashler et al., 2001).

By applying dominant cognitive processing capacity to investors, Kahneman (1973) suggests that attention is a scarce cognitive resource in which investors pose little of it. Based on such intuition, research has found that individual investors are characterized by having limited attention and processing abilities (Seasholes \& Wu, 2007). Recent studies have provided a framework that positions investors' limited attention as effecting asset pricing statistics and dynamics (Da et al., 2011; Joseph et al., 2011). Hence, individuals suffer from bounded rationality. When being faced with a large amount of information, they are restricted in ter ms of how much of that information they can actually process. Therefore, individual investors who are faced with a large amount of information will then be faced with the problem of analyzing these them in pursuit of making an accurate stock purchasing decision. Behavioral based theories have asserted that events that catch the attention of an individual investor will assist in narrowing down the ranges of stocks that they are prone to be chosen from. Therefore, some individual investors buy stocks that grab their attention (Barber \& Odean, 2008). This perception implies that prices may not reflect all available information due to limited investor attention. Hence, investor behavior contrasts traditional finance theories that imply efficiency in markets. 
The decision-making process of an investor is somewhat intricate. The irrationality of investor trading activities is a result of how investors perceive present information. Sufficient devotion has been given to a certain stock at the time prior to engaging in a certain transaction. A single investor processes information on a given stock to infer their apparent values. The investor initially generates a course of signals via information dispensation (Peng \& Xiong, 2006). Such process is affected by the individual investors' attention allocation and restraints. The more attention allocated to a certain factor, the more information processing is generated, and the gathered signals are incorporated into an investors' beliefs. The investor finally makes the final decision based on the process of information gathering triggered by his attention. Hence, an investor might have a biased reaction to given information (Hirshleifer, 2001), which causes investors to concentrate on certain information and neglect other information.

In addition, previous studies ratify the importance of the quality of information signals and the influence on investor trading behavior. Information from trustworthy sources emphasizes the quality of trades than that from less reliable sources (Epstein \& Schneider, 2008). The financial advice received by professional vendors should lead to more rational investment decision-making, and impacting positively on trading (Fischer \& Gerhardt, 2007). However, there has been a growing appreciation of the value of information collection across different digital programs such as online searches (Vlatakis \& Markellos, 2012). Internet users have been a growing segment, and an evident alteration is witnessed in the production and consumption of information. This has transformed the way investors collect information, especially when such information is less costly than other information vendors. The easiness and availability of information through these vendors increase the reliance on the mechanisms in decision making of investing. Hence investor attention is reflected in the volume of online searching.

The Attention Hypothesis of Barber \& Odean (2008) proposes that increased attention leads to increased purchasing. this activity push prices and returns higher, temporarily, followed by a reversal. It is well recognized that trading volume of a given stock increases on days with release of current information (Karpoff, 1987). This could be attributed, when considering high trading volumes, to high attention related to a certain stock, which could cause a price increase in the near future. This is especially effective with the lenience of applicability of information due to the internet. As mentioned previously, the increase reliance on online searches has been dominate recently and online searches can be used as an indicator for investor attention (Da et al., 2011). Based on the work of Barber and Odean (2008), and other scholars that have followed, investor attention is found to effect stock returns. Such studies have reflected upon developed markets in which they are characterized as being efficient. Hence, attention-grabbing stocks in such developed markets might have more influence on stock prices when being compared to underdeveloped markets. In the study an emphasize on an undeveloped context in which the Saudi market is examined for potential attention driving decision making.

The study highlights three apparent variables that are likely to be linked with attention-grabbing events and reflect on internet users: search indictors, trading volume, and returns. While none of these variables is a true representation for attention, all three are useful indicators as used in Barber and Odean (2008) and Da et al (2011).

\section{Materials and Methods}

This study will test whether changes in stock prices are triggered by investor attention. When attention of investors is set on a certain stock, then an increase of trading volume should be noticed. Abnormally heavy stock volume will be considered a variable in testing an investor's attention to that stock. A higher level of volume reflects, higher levels of investors' attention. To accurately categorize stocks as witnessing high abnormal trading volume, an analysis method is used in following Barber \& Odean (2008). The study concentrates on the real estate sector due to the importance of in Saudi with massive investment undertaken by the government in that sector in which the vast growth of such sector is evident. Also, information on such sector is important to investors in which the Saudi economy is witnessing vast development in this sector. 
Another indicator of attention that is used is Google's Search Volume Index (SVI) (Da et al., 2011). As previously mentioned, the Internet has become an essential search tool in which individuals reflect upon their interest in their searching queries. Google, to be precise, is the most popular search engine in which it captures about $70 \%$ in market share. Google saves all queries typed in the Google search bar and information about the number of searches of a given topic or issue, and this is available to the public. Hence SVI is used to capture attention. In addition, the stock change in trading volume for each individual stock in the real estate sector is used by calculating proxy for attention using volume-based data

After conducting the previous analysis, I will concentrate on the stocks with the highest abnormal increase in volume that will be tested in this paper. Investor attention will be tested to see whether news or price changes might trigger an individual's attentiveness. Hence the model in this paper will be as follows:

$R_{t}=b_{1}+b_{2} V_{t}+b_{3} S V_{t} e_{t}$

In which

$\mathrm{V}_{\mathrm{t}}=$ is the change in volume traded in time $\mathrm{t}$ to the average volume

$\mathrm{R}_{\mathrm{t}}=$ is the change of the price of the stock at time $\mathrm{t}$

SVI= Google's search volume index

First, we start by running a Fama Macbeth cross-sectional regression and then we move on to investigate the induvial time-series regressions.

Table 1: This table shows the descriptive statistics for the different firms.

\begin{tabular}{|c|c|c|c|c|c|c|c|c|}
\hline & RARRIYADH & $\begin{array}{l}\text { DAR- } \\
\text { ARKAN }\end{array}$ & RECONCITY & REMAAR & $\begin{array}{l}\text { JABAL- } \\
\text { OMAR }\end{array}$ & RMAKKAH & REALESTATE & RTIABA \\
\hline \multicolumn{9}{|c|}{ Panel A (Return) } \\
\hline Mean & $-8.39 E-05$ & -0.000701 & 0.000153 & $\begin{array}{l}- \\
0.000135\end{array}$ & 0.001754 & 0.000900 & -0.000445 & $-9.68 \mathrm{E}-05$ \\
\hline Median & 0.000000 & -0.001597 & -0.000782 & 0.000000 & 0.000416 & -0.000575 & -0.000678 & 0.000000 \\
\hline Maximum & 0.097930 & 0.096386 & 0.099493 & 0.098712 & 0.099010 & 0.099276 & 0.098326 & 0.096925 \\
\hline Minimum & -0.098649 & -0.099424 & -0.099617 & $\begin{array}{l}- \\
0.098525\end{array}$ & 0.098375 & -0.085344 & -0.099424 & $\begin{array}{l}- \\
0.098888\end{array}$ \\
\hline Std. Dev. & 0.019986 & 0.023340 & 0.028996 & 0.026983 & 0.023403 & 0.020881 & 0.022937 & 0.018699 \\
\hline Skewness & -0.146888 & -0.001527 & 0.096947 & $\begin{array}{l}- \\
0.006480\end{array}$ & 0.355000 & 0.884186 & -0.606070 & $\begin{array}{l}- \\
0.120515\end{array}$ \\
\hline Kurtosis & 10.76183 & 7.429739 & 6.267974 & 6.975853 & 7.774983 & 8.979094 & 7.492428 & 12.05542 \\
\hline Jarque-Bera & 1199.104 & 389.9990 & 213.0053 & 314.1756 & 463.1781 & 772.6745 & 430.3175 & 1630.916 \\
\hline Probability & 0.000000 & 0.000000 & 0.000000 & 0.000000 & 0.000000 & 0.000000 & 0.000000 & 0.000000 \\
\hline Sum & -0.040019 & -0.334545 & 0.073140 & $\begin{array}{l}- \\
0.064494\end{array}$ & 0.836808 & 0.429421 & -0.212033 & $\begin{array}{l}- \\
0.046191\end{array}$ \\
\hline Sum Sq. Dev. & 0.190131 & 0.259308 & 0.400206 & 0.346578 & 0.260716 & 0.207543 & 0.250426 & 0.166426 \\
\hline \multicolumn{9}{|c|}{ Panel B (Volume) } \\
\hline
\end{tabular}




\begin{tabular}{|c|c|c|c|c|c|c|c|c|}
\hline Mean & 0.999061 & 1.001743 & 1.000410 & 1.000772 & 1.000858 & 1.000002 & 0.999787 & 1.000069 \\
\hline Median & 0.782482 & 0.750352 & 0.667387 & 0.689635 & 0.590677 & 0.557413 & 0.572406 & 0.531192 \\
\hline Maximum & 5.394833 & 6.515117 & 7.047504 & 6.668261 & 10.61222 & 15.46730 & 15.22783 & 10.05823 \\
\hline Minimum & 0.074352 & 0.111141 & 0.088305 & 0.086965 & 0.036651 & 0.037077 & 0.043003 & 0.027064 \\
\hline Std. Dev. & 0.769511 & 0.799580 & 1.013766 & 0.966865 & 1.358954 & 1.519097 & 1.348279 & 1.328832 \\
\hline Skewness & 2.063201 & 2.003799 & 2.744906 & 2.467623 & 3.760350 & 4.833428 & 4.905843 & 3.040548 \\
\hline Kurtosis & 9.276920 & 9.482225 & 12.16284 & 10.90505 & 21.15539 & 34.99887 & 40.25482 & 14.84339 \\
\hline Jarque-Bera & 1121.485 & 1154.342 & 2267.651 & 1726.073 & 7675.308 & 22207.84 & 29498.30 & 3522.755 \\
\hline Probability & 0.000000 & 0.000000 & 0.000000 & 0.000000 & 0.000000 & 0.000000 & 0.000000 & 0.000000 \\
\hline Sum & 476.5520 & 477.8316 & 477.1954 & 477.3684 & 477.4093 & 477.0011 & 476.8986 & 477.0331 \\
\hline Sum Sq. Dev. & 281.8621 & 304.3199 & 489.1951 & 444.9777 & 879.0553 & 1098.443 & 865.2997 & 840.5181 \\
\hline Observations & 477 & 477 & 477 & 477 & 477 & 477 & 477 & 477 \\
\hline
\end{tabular}

\section{Results and Discussion}

In the real estate sector of the Saudi market, all information regarding past prices and trading volume is derived. Data for returns and average trading volumes are winsorized to rule out any outliers that might have been present and to narrow down the ranges of the data given. A Fama Macbeth regression is conducted between stock returns and trading volumes for all the panel and a simple OLS time series regression is examined for all firms individually. Lagged return values for the stock returns is controlled for.

\section{Table 2}

In this table, the Newey West coefficients and standard errors of the model are displayed.

\begin{tabular}{ll}
\hline Fama-MacBeth Two-Step procedure (Newey SE) \\
\cline { 2 - 2 } & \\
\hline & $0.098^{\star \star \star}$ \\
Retunt-1 & $(3.22)$ \\
& $0.005^{\star \star \star}$ \\
Vol & $(5.57)$ \\
& -0.001 \\
Constant & $(-0.65)$ \\
& \\
R-Squared & 0.418 \\
F-Stat & 20.674 \\
Obs & 3807 \\
\hline .1
\end{tabular}

${ }^{* * *} p<0.01,{ }^{* *} p<0.05,{ }^{*} p<0.1$

In Table 2 it clearly shows a significant relation in the cross-section of returns. 
Table 3: In this table, the robust coefficients and standard errors of the model are displayed.

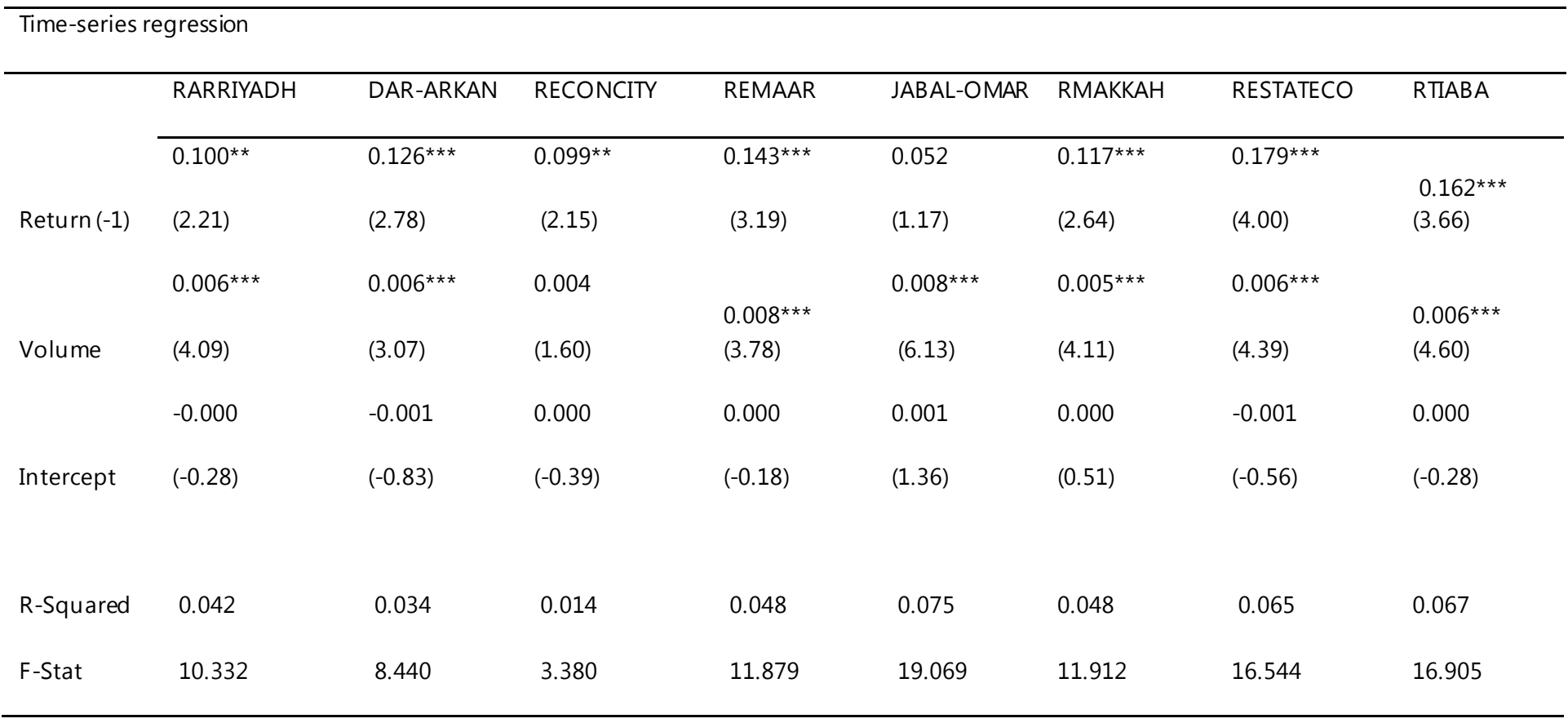

${ }^{* * *} p<0.01,{ }^{* *} p<0.05,{ }^{*} p<0.1$

It could be seen that the output of the result sheets reflects upon significance with trading volume for most of the firms. The lagged values of returns also presented to be significance for most of the firms. This reflects upon the effect of current changes in trading volume on stock returns. The emphasis is that the change in trading volume is automatically reflected upon stock returns. However, when looking at our regressions we see that the F-statistics and R-squared values are low suggesting that the model should be controlled for more variables that might explain the variation of stock return.

Up to now the regressions do not incorporate the SVI variable that will is proposed to capture investors' attention. When looking at Google's trends engine we could see that it is an English based engine that incorporates all languages. Previous studies using Google trends for indication of stock purchases used the individual stock ticker to reflect upon searches. However, when looking when reflecting upon Saudi stock tickers it is seen that the tickers are indicated and coded as numerical encryptions, to reflect upon the number of searches on a certain number which might represent conflicting results.

Hence, the search volume of the stocks is investigated by using the names of institution using Arabic and English names. When performing this procedure, it is found that only Jabal Omar stocks have been searched in high reportable volumes. This could be reflected to several factors mainly the fact that the tickers are reflected as numerical codes which has concealed valuable results. Hence, the stocks that have not shown sufficient search volume have been exclude in which only Jabal Omar was studied.

Another OLS regression in done but this time the SVI variable is incorporated with the volume. The SVI only indicated monthly searching measurements. Hence, the average of returns and trading volumes of stock across the studied timeframe is taken to have equivalent levels in data.

All variable has been seen significant at the one percent level indicating an association with the dependent variable. This reflects upon that search volume and trading volumes reflect immediately on stock returns. Hence the attention-grabbing factors that are indicated by increased trading volume and willingness of investor to search for such investment have affected return in a positive direction. However, such results are not generalizable to all stocks but present valuable insight on the attention related aspects of decision making. 


\section{Table 4}

In this table, the robust coefficients and standard errors of the model are displayed.

Time-series regression

\begin{tabular}{ll}
\hline & \multicolumn{1}{c}{ Jabal Omar } \\
\cline { 2 - 2 } Volume & $0.003^{\star * \star}$ \\
& $(7.970)$ \\
SVI & $4.49 \mathrm{e}-05^{\star * *}$ \\
& $(6.126)$ \\
Intercept & $-0.004^{\star * *}$ \\
& $(-8.151)$ \\
R-Squared & \\
F-Stat & 0.195 \\
\hline 0.1 & 57.328 \\
\hline
\end{tabular}

The overall fitness of the model was low in which the R-squared and F-statistics are moderate. Hence, other unobservable variables should have been incorporated in the model that might reflect upon a better fit for the given model. Also, the lack of search volumes for other stocks in the same sectors has omitted valuable insights that might have evolved when conducting this study. Studies should investigate a more wider time frame to inspect the effects of attention on an investor's decision making. In addition, future studies should look at other plausible proxies that can be used to capture attention especial in markets such as the Saudi market which might have other specific aspects than a possible candidate to proxy for.

\section{Main Text (Review only)}

This section may be divided into subsections or may be combined.

\section{Conclusions}

Existing studies on investor attention has looked at the relationship of the investors cognitive capabilities and its reflection on stock prices (Barber \& Odean, 2008). The studies have reflected upon developed markets that showed that investor attention reflects upon stock prices in an impending period in which prices fall after. However, in our study we see that the context of the Saudi stock market differs in which the stock prices correspondingly adjust prices due to increases in $a=i n v e s t o r$ attention. This could be due to the less efficiency in Saudi stock markets in which such behavior would directly affect stock prices.

Hence, such study needs more modification in which other variable should be added that might also justify stock price movements. Also, other indicators of attention should be recognized that might not be reflected in SVI. The Saudi community is well known with its digital usage in which other programs are used that might reflect upon attention. These could be in the form of application found on cell phones that connect individuals together in which such applications are being used to broadcast news, whether accurate or not. More studies 
are needed to be looked upon to true narrow down the actual effects of investors' attention and if it reflects upon Saudi stock prices.

\section{Data Availability (excluding Review articles)}

This study will aim to analyze the Saudi real estate stocks historical data records, which is reflected in market measures. In 2008, the Saudi stock exchange confirmed that the dominant investors of stocks are individual investors (Haddad \& Hakim, 2008). According to Riyadh based Jadwa Investment institute, individual investors in Saudi stock market accounted for $95 \%$ of the traders. Hence, the types of investments that will be considered are common stock purchases. Investments in mutual funds, bonds or any type of financial instrument will be excluded from our analysis. We will focus on individual investors and exclude institutional investors as mentioned previously seeing that the variables reflect upon individual human traits. We will rely on data retrieved from Tadawul regarding common stock information in a timeframe that starts from January 2014 till present date. Also, we will rely on Google SVI to retrieve information regarding the volume of enquiries regarding a certain stock. We will also look at Compustat for information on the Saudi stock market if the Saudi index TASI will be considered.

\section{References}

1. Barber, B. M., \& Odean, T. (2008). All that glitters: The effect of attention and news on the buying behavior of individual and institutional investors. The review of financial studies, 21(2), 785-818.

2. Chang, C. H. (2008). THE IMPACT OF BEHAVIORAL PITFALLS ON INVESTORS'DECISIONS: THE DISPOSITION EFFECT IN THE TAIWANESE WARRANT MARKET. Social Behavior and Personality: an international journal, 36(5), 617-634.

3. Da, Z., Engelberg, J., \& Gao, P. (2011). In search of attention. The Journal of Finance, 66(5), 1461-1499.

4. Epstein, L. G., \& Schneider, M. (2008). Ambiguity, information quality, and asset pricing. The Journal of Finance, 63(1), 197-228.

5. Fama, E. F. (1965). The behavior of stock-market prices. The journal of Business, 38(1), 34-105.

6. Fama, E. F. (1965). Portfolio analysis in a stable Paretian market. Management science, 11(3), 404-419.

7. Fischer, R., \& Gerhardt, R. (2007, August). Investment mistakes of individual investors and the impact of financial advice. In 20th Australasian Finance \& Banking Conference.

8. Haddad, M., \& Hakim, S. (2008). Irrational exuberance on the Saudi stock exchange. In ERF Conference Paper No (Vol. 152008051).

9. Hirshleifer, D. (2001). Investor psychology and asset pricing. The Journal of Finance, 56(4), 1533-1597.

10. Joseph, K., Wintoki, M. B., \& Zhang, Z. (2011). Forecasting abnormal stock returns and trading volume using investor sentiment: Evidence from online search. International Journal of Forecasting, 27(4), 11161127.

11. Kahneman, D. 1973Attention and effort.

12. Kahneman, D., \& Tversky, A. (2013). Prospect theory: An analysis of decision under risk. In Handbook of the fundamentals of financial decision making: Part I (pp. 99-127).

13. Karpoff, J. M. (1987). The relation between price changes and trading volume: A survey. Journal of Financial and quantitative Analysis, 22(1), 109-126. 
14. Odean, T. (1999). Do investors trade too much?. American economic review, 89(5), 1279-1298.

15. Pashler, H., Johnston, J. C., \& Ruthruff, E. (2001). Attention and performance. Annual review of psychology, 52(1), 629-651.

16. Peng, L., \& Xiong, W. (2006). Investor attention, overconfidence and category learning. Journal of Financial Economics, 80(3), 563-602.

17. Samargandi, N., Fidrmuc, J., \& Ghosh, S. (2014). Financial development and economic growth in an oilrich economy: The case of Saudi Arabia. Economic Modelling, 43, 267-278.

18. Seasholes, M. S., \& Wu, G. (2007). Predictable behavior, profits, and attention. Journal of Empirical Finance, 14(5), 590-610.

19. Vlastakis, N., \& Markellos, R. N. (2012). Information demand and stock market volatility. Journal of Banking \& Finance, 36(6), 1808-1821 